\title{
EAl Endorsed Transactions

\section{Maiden Application of Meta-Heuristic Techniques with Optimized Integral minus Tilt-Derivative Controller for AGC of Multi-area Multi-Source System}

\author{
Sanjeev Kumar Bhagat ${ }^{1, *}$, Naladi Ram Babu${ }^{1}$, Lalit Chandra Sakia ${ }^{1}$ and Dhenuvakonda Koteswara Raju ${ }^{1}$ \\ ${ }^{1}$ National Institute of Technology Silchar, Assam, INDIA - 788010
}

\begin{abstract}
This article presents a new meta-heuristic algorithm optimized secondary controller called Integral minus Tilt-Derivative (I-TD) for automatic generation control of three area multi-source system. Area- 1 comprises of thermal and solar thermal units, area- 2 comprises of two thermal units and area- 3 comprises of thermal and wind systems. Comparison of system responses using proposed I-TD controller and some other commonly used controller revels better dynamics characteristics of the proposed one. Dynamic responses of the system corresponding to various meta heuristic optimization technique like firefly algorithm (FA), grey-wolf optimization (GWO), grass-hopper algorithm (GHA) explore that GHA provides slightly better dynamics than the other and also converges faster. Further, sensitivity analysis suggests that system dynamics with GHA optimized I-TD controller at various loading conditions are robust and are not reset again.
\end{abstract}

Keywords: automatic generation control, firefly algorithm, grass-hopper algorithm, grey-wolf optimization and sensitivity analysis.

Received on 12 November 2019, accepted on 30 April 2020, published on 14 May 2020

Copyright (C) 2020 Sanjeev Kumar Bhagat et al., licensed to EAI. This is an open access article distributed under the terms of the Creative Commons Attribution licence (http://creativecommons.org/licenses/by/3.0/), which permits unlimited use, distribution and reproduction in any medium so long as the original work is properly cited.

doi: 10.4108/eai.13-7-2018.164557

*Corresponding author. Email:sksanju1070@gmail.com

\section{Introduction}

Automatic generation control (AGC) is defined as the method of suppressing deviations in frequency and tie-line power interchange between the control-areas. These deviations are caused by the mismatch among power generation and load demand. AGC aims to maintain the systems scheduled tie-line power and frequency within prescribed value during sudden disturbances [1, 2]. AGC has two control loops; primary control loop controls the speed-governing action of generating units and the secondary control loop restores the system frequency with in prescribe limits by adjusting the load reference. The preliminary AGC studies were carried out by Elgard et al. [3] with thermal systems of single-area and further extended to multi-area systems [4 - 6]. To make system more practical the non-linarites such as generation rate constraints (GRC), governor dead band (GDB) are considered in the system modelling [7 - 8] which deteriorate initial responses the system.

The exhaust of conventional sources and their harmful impacts on global environment led to the use of renewable sources in interconnected power system. Renewables such as solar, wind etc. makes the power system liberalize and contributes in reducing the gap between power generation and load demand. Renewables like solar and wind dominates over other renewables due to its abundance in nature. Renewable like solar [9], wind [10, 11] etc., are reported in AGC of two-area only. Therefore, it gives the opportunity to carry out the AGC studies with multi-area multi-source system along with renewable integration which provides scope for further investigations. 


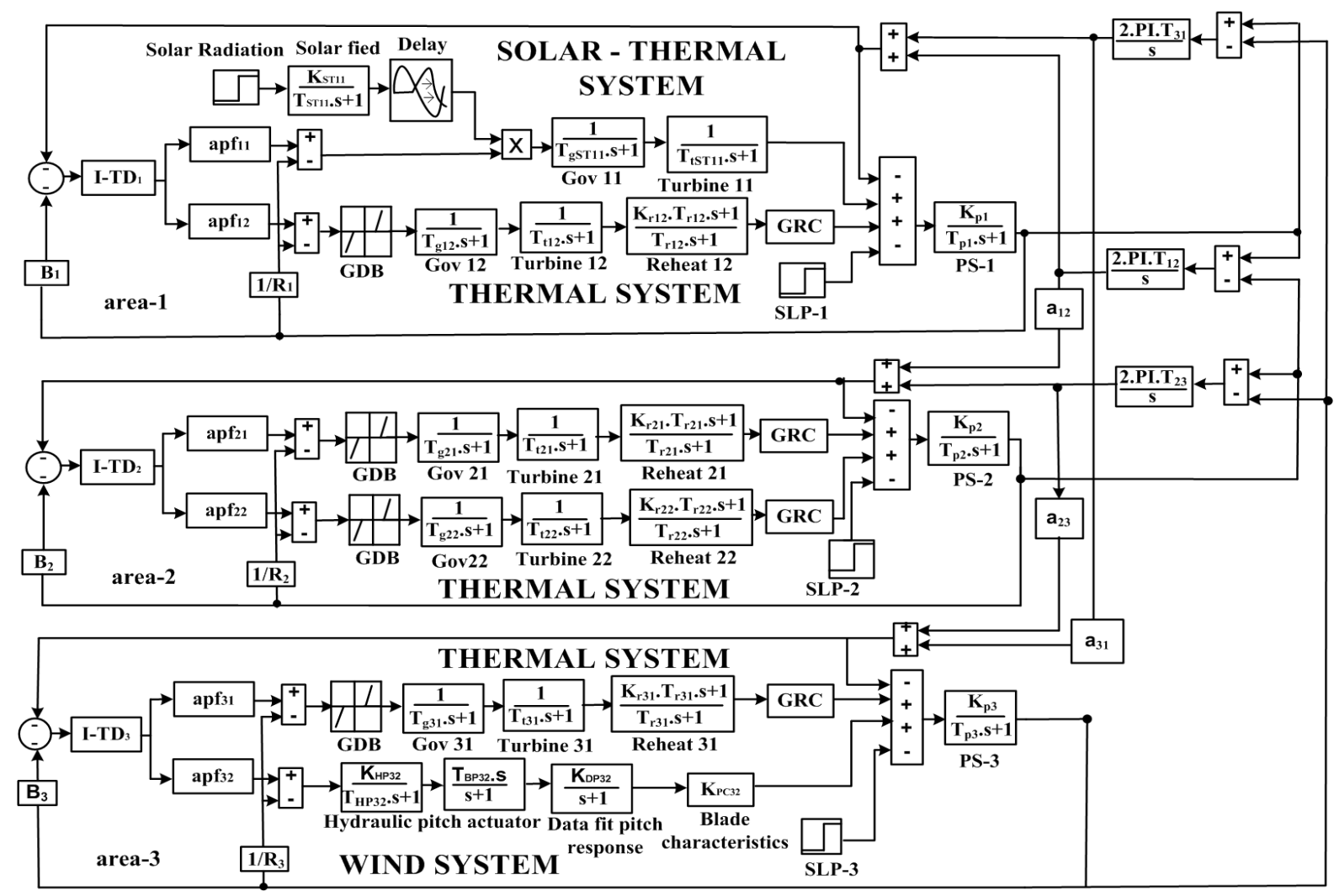

Figure 1. Transfer function model of three-area multi-source system

To nullify the steady state error in frequency, tiepower and to reduce the subsequent oscillations of system under disturbance condition, secondary controllers are utilized. Many secondary controllers have been reported in AGC such as PI, PID [12], fractional-order (FO) like FOPI, FOPID [13], and cascaded controller like PD-PI, PID-PID [14] etc. Lurie et al. [15] developed a new controller named by tilt-integral-derivative (TID) having the advantages of both integer order and FO controllers. TID provides an improved feedback control with more tuning parameters than PID and provides flexibility [16 18]. Derivative kick is generated due to the presence of derivative control in forward path $[19,20]$. Due to this, the industrial engineers have resigned the controller as I-TD. Surprisingly, the application of I-TD has not been utilized in AGC studies. This provides the scope for further investigations.

System performance not only depends on the selection of controller but it also on depends on the optimal tuning of its parameters. Optimal tuning can be achieved by various optimization techniques such as classical and evolutionary algorithms (EA). As the number of variables increases, the classical approach will be laborious and provides sub-optimum results. Moreover, the optimal results obtained with classical techniques stick at local optima and do not provide global optimum values. Whereas, heuristic/meta heuristic algorithms are the techniques that finds the solution close to optimum level with acceptable calculative cost. They are easy to implement with large number of variables and provides faster convergence over classical techniques. EAs like heuristic/meta-heuristic algorithms provides optimal search with global optimum value $[21,22]$. EAs such as differential evolution [23], bacterial foraging [24], cuckoo search algorithm [25], firefly algorithm (FA) $[26,27,28]$, grey wolf optimization (GWO) [29, 30] etc. are available in literature. Mirjalili et al. [31, 32] have presented an optimization technique called grasshopper algorithm (GHA) that works on the swarming behavior of grass hopers. However, the applications of GHA optimization technique in multi-area multisource AGC system with solar-thermal, thermal and wind systems are not found. This provides scope for further investigations.

Sinha et al. [33] demonstrated the sensitivity analysis of the controller at varied conditions such as system loading and inertia constant [34] with BF and FA technique. Moreover, the application of GHA in AGC can be extended to perform sensitivity analysis at different loading conditions with I-TD controller. This provides scope for further investigations.

From the above, the objectives are as follows:

a) To develop a three-area multi-source system constituting thermal, solar thermal and wind.

b) To compare the systems dynamics with various controllers like PID, TID and I-TD controller with GHA in order to find the best controller.

c) To compare the system dynamics with the best controller found in (b) by using various 
evolutionary algorithms such as FA, GWO, and GHA and in order to find the best optimization technique.

d) To perform a sensitivity analysis of the best controller under different loading conditions.

\section{System Investigated}

The investigated system comprises of thermal-solar thermal units in area-1, thermal-thermal units in area-2, and thermal-wind unit in area- 3 with area capacity ratio as $1: 2: 4$ is considered. The input for the solar-thermal unit is fixed solar insolation of $0.01 \mathrm{p} . \mathrm{u} \mathrm{W} / \mathrm{m}^{2}$ and a delay of $0.02 \mathrm{~s}$ is considered. The area participation factor (apf) of 0.5 is selected as arbitrarily for each generating unit. The thermal system is provided with GRC of $3 \%$ per minute, $\pm 0.06 \%$ GDB and droop of $4 \%$ are taken from $[7,8]$.

Power generation in power plants varies at a specified rate with generation limits as GRC. The speed change constraint within which the valve turbine position remains same is known as GDB. For stable and satisfactory parallel operation of several units, the speed governor is provided with droop characteristics. The values of GRC, GDB, and droop are chosen in such a way to reduce the wear and tear of the boiler, governor, and turbine of the thermal system in order to achieve long term operation.

The transfer function model of the investigated system is shown in Figure 1 and the nominal parameters of thermal, solar-thermal and wind units are taken from [10]. Various optimization techniques like FA, GWO and GHA are utilized for simultaneous optimization of controller gains and other parameter with integral squared error $\left(\mathrm{J}_{\mathrm{ISE}}\right)$ as performance index subjecting to $1 \%$ step load perturbation (SLP) in area-1 is given by (1).

$$
\mathrm{J}_{\text {ISE }}=\int_{0}^{\mathrm{t}}\left(\left(\Delta \mathrm{F}_{\mathrm{i}}\right)^{2}+\left(\Delta \mathrm{P}_{\text {tiei-j }}\right)^{2}\right) \mathrm{dt}
$$

where $\mathrm{J}_{\text {ISE }}$ is the objective function, $\mathrm{i}, \mathrm{j}$ are area number ( $\mathrm{i}$, $\mathrm{j}=1,2$ and 3 where $\mathrm{i} \neq \mathrm{j}) \Delta \mathrm{F}_{\mathrm{i}}$ deviation frequency in $\mathrm{i}^{\text {th }}$ area, $\Delta \mathrm{P}_{\text {tie } i-\mathrm{j}}$ is tie power deviation among area $\mathrm{i}-\mathrm{j}$. The system is modelled in Simulink with FOMCON tool box and the optimization technique is coded in MATLAB 2015a software.

\section{The Proposed I-TD Controller}

Lurie et al [15] developed a new secondary controller named by TID. It has the advantages of both integer order and fractional order controller. The structure of TID is similar to PID, but the proportional term of PID is multiplied with $1 / \mathrm{s}^{\wedge}(1 / \mathrm{N})$. The transfer function of PID and TID are given by (2) and (3).

$$
\mathrm{G}_{\mathrm{PID}}(\mathrm{s})=\mathrm{K}_{\mathrm{P}, \mathrm{PIDi}}+\frac{\mathrm{K}_{\mathrm{I}, \mathrm{PID} \mathrm{i}}}{\mathrm{s}}+\mathrm{K}_{\mathrm{D}, \mathrm{PIDi}} \mathrm{s}
$$

where $\mathrm{K}_{\mathrm{P}, \mathrm{PIDi}}$ is proportional gain, $\mathrm{K}_{\mathrm{I}, \mathrm{PIDi}}$ is integral gain and $\mathrm{K}_{\mathrm{D} \text {,PIDi }}$ is derivative gain of PID controller.

$$
\mathrm{G}_{\mathrm{TID}}(\mathrm{s})=\frac{\mathrm{K}_{\mathrm{T}, \mathrm{TIDi}}}{\left.\mathrm{s} / \mathrm{T}_{\mathrm{TDD}_{\mathrm{i}}}\right)}+\frac{\mathrm{K}_{\mathrm{I}, \mathrm{TID} \mathrm{i}}}{\mathrm{s}}+\mathrm{K}_{\mathrm{D}, \mathrm{TID}} \mathrm{s}
$$

where $\mathrm{K}_{\mathrm{T}, \mathrm{TIDi}}$ is tilt gain , $\mathrm{K}_{\mathrm{I}, \mathrm{TIDi}}$ is integral gain , $\mathrm{K}_{\mathrm{D} \text {,TIDi }}$ is derivative gain and $\mathrm{N}$,TIDi is real number $(\mathrm{N}, \mathrm{TIDi} \neq 0)$ of TID controller.

Due to the presence of derivative control in forward path derivative kick is generated, which is objectionable in electronic circuits. In order to overcome this, the industrial engineers have redesigned the structure of TID as I-TD by tilt and derivative term in forward path and integral term in feedback path [15]. However, this I-TD controller is not yet investigated for three area multi-source AGC studies. The structure of I-TD controller is shown in Figure 2 and its transfer function is given by (4).

$$
\mathrm{G}_{\mathrm{I}-\mathrm{TD}}(\mathrm{s})=\frac{\mathrm{K}_{\mathrm{I}, \mathrm{I}-\mathrm{TD}}}{\mathrm{s}}-\left(\frac{\mathrm{K}_{\mathrm{T}, \mathrm{I}-\mathrm{TDi}}}{\mathrm{s}^{\left(1 / \mathrm{I}_{\mathrm{I}-\mathrm{TDi}}\right)}}+\mathrm{K}_{\mathrm{D}, \mathrm{I}-\mathrm{TDi}} \mathrm{s}\right)
$$

where, $\mathrm{K}_{\mathrm{T}, \mathrm{I}-\mathrm{TDi}}$ is tilt gain, $\mathrm{K}_{\mathrm{I}, \mathrm{I}-\mathrm{TDi}}$ is integral gain, $\mathrm{K}_{\mathrm{D}, \mathrm{I}-}$ TDi is derivative gain and $\mathrm{N}_{\mathrm{I}-\mathrm{TDi}}$ is real number ( $\mathrm{N}$,TIDi $\neq 0$ ) of I-TD controller. The I-TD controller gains and other parameters are simultaneously optimized by FA, GWO and the GHA technique by subjecting to a set of constraints in (5) with minimization of objective function in (1).

$$
\begin{gathered}
0 \leq \mathrm{K}_{\mathrm{P} . \mathrm{PIDi}} / \mathrm{K}_{\mathrm{T}, \mathrm{TIDi}} / \mathrm{K}_{\mathrm{T}, \mathrm{I}-\mathrm{TDi}} \leq 1 \\
0 \leq \mathrm{K}_{\mathrm{I}, \mathrm{PIDi}} / \mathrm{K}_{\mathrm{I}, \mathrm{TIDi}} / \mathrm{K}_{\mathrm{I}, \mathrm{I}-\mathrm{TDi}} \leq 1 \\
0 \leq \mathrm{K}_{\mathrm{D}, \mathrm{PIDi}} / \mathrm{K}_{\mathrm{D}, \mathrm{TIDi}} / \mathrm{K}_{\mathrm{D}, \mathrm{I}-\mathrm{TDi}} \leq 1 \\
2 \leq \mathrm{N}_{\mathrm{TIDi}} / \mathrm{N}_{\mathrm{I}-\mathrm{TDi}} \leq 7
\end{gathered}
$$

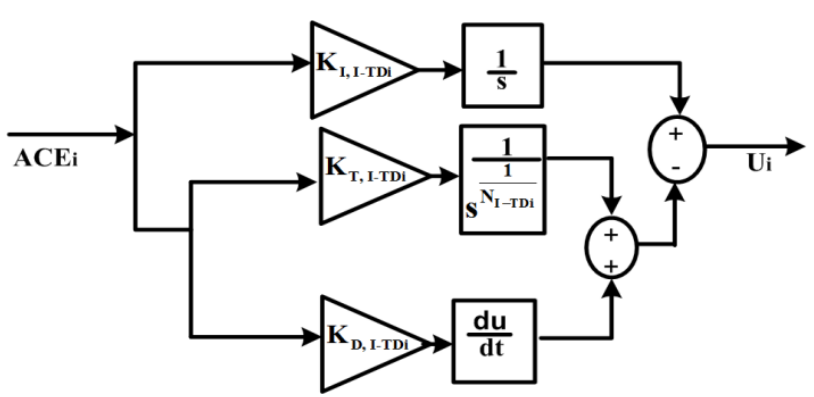

Figure 2. Transfer function model of I-TD controller

\section{System Investigations with various Heuristic Algorithms}

\subsection{Firefly Algorithm}

Firefly algorithm (FA) was developed by yang et al. [26 - 28]. It depends on the brightness/attractiveness of fireflies. The three main characteristics of FA are (a) Based on brightness level each firefly attracts others, (b) Higher brightness firefly has high attraction level to others, vice-versa and (c) Lower brightness firefly moves toward higher brightness firefly.

The attractiveness of a firefly depends on the distance between fireflies. In fact, every individual firefly will have its own brightness. The mathematical 
relation of firefly with brightness (1), source brightness $\left(I_{s}\right)$ and distance (r) is given by equation (6).

$$
1(r)=\frac{I_{S}}{r^{2}}
$$

In a medium with constant light coefficient $(\gamma)$ and original brightness $\left(\mathrm{I}_{0}\right)$ the firefly brightness can be written as (7).

$$
\mathrm{I}_{\mathrm{S}}=\mathrm{I}_{0} \mathrm{e}^{-\gamma \mathrm{r}}
$$

As the natural behavior of firefly attractiveness is proportional to brightness seen by the next firefly. The attractiveness of firefly can be defined equation (8)

$$
\beta=\beta_{0} \mathrm{e}^{-\gamma \mathrm{r}^{2}}
$$

where $\beta_{0}$ attractiveness at $r=0$. Based on its brightness (objective function) the fireflies with lower brightness mates with fireflies of higher brightness in order to produce new solutions. The movement of firefly (a) is attracted to another firefly (b) having more brightness is given by (9).

$$
X_{a}=\left(1-\beta_{a, b}\right) \cdot X_{a}+\beta_{a, b} X_{a}+\alpha(\text { rand - 0.5) }
$$

Therefore, in FA previous solution is updated by a new solution based on their brightness level. The Flow chart of FA is shown in Figure 3. (a). The best solution is considered with good fitness. The tuned parameters of FA are number of firefly $=30$, maximum generation $=100$, $\beta=0.3, \alpha=0.4$ and $\gamma=0.6$

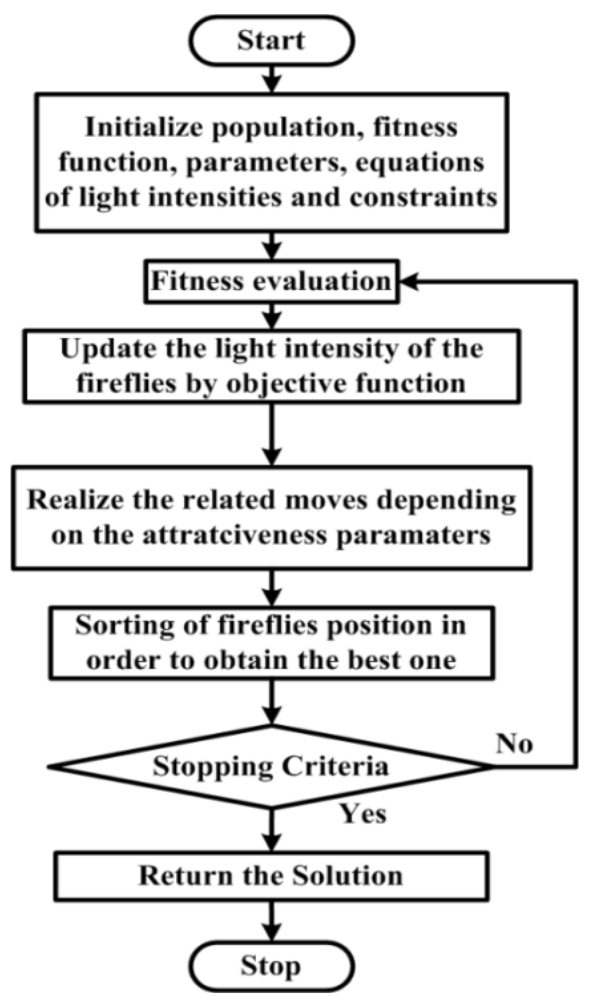

Figure 3. (a) Flowchart of Firefly algorithm

\subsection{Grey Wolf Optimization}

Seyedali Mirjalili et al. [29] developed grey-wolf optimization (GWO) [30]. Its main characteristics are searching for prey and hunting. These wolfs move in a group of $5-12$ in number called as pack. There are four members involves in a pack such as alpha $(\alpha)$, beta $(\beta)$, delta $(\delta)$ and omega $(\omega)$ and each member has own responsibility to make pack strong during searching and hunting the prey $[29,30]$. The mathematical representation of prey can be written as (10) and (11).

$$
\begin{gathered}
\overrightarrow{\mathrm{D}}=\left|\overrightarrow{\mathrm{C}} \overrightarrow{\mathrm{X}_{\mathrm{p}}}(\mathrm{t})-\overrightarrow{\mathrm{X}}\right| \\
\overrightarrow{\mathrm{X}}(\mathrm{t}+1)=\overrightarrow{\mathrm{X}_{\mathrm{p}}}(\mathrm{t})-\overrightarrow{\mathrm{A}} \cdot \overrightarrow{\mathrm{D}} \\
\overrightarrow{\mathrm{A}}=2 \overrightarrow{\mathrm{a} \vec{r}_{1}}-\overrightarrow{\mathrm{A}} \\
\overrightarrow{\mathrm{C}}=2 \overrightarrow{\mathrm{r}_{2}}
\end{gathered}
$$

where current iteration $(\mathrm{t})$, vector coefficient (A and C) and prey position $\left(\mathrm{X}_{\mathrm{p}}\right), \mathrm{x}$ is grey wolf vector position (a) is decreasing coefficient from 2 to 0 and $r_{1}, r_{2}$ are random vector. Similarly, the hunting equation of pack member can be written as equation (12) to (14).

$$
\left.\begin{array}{r}
\overrightarrow{\mathrm{D}}_{\alpha}=\left|\overrightarrow{\mathrm{C}}_{1} \overrightarrow{\mathrm{X}_{\alpha}}(\mathrm{t})-\overrightarrow{\mathrm{X}}\right| \\
\overrightarrow{\mathrm{D}}_{\beta}=\left|\overrightarrow{\mathrm{C}}_{2} \overrightarrow{\mathrm{X}_{\beta}}(\mathrm{t})-\overrightarrow{\mathrm{X}}\right| \\
\overrightarrow{\mathrm{D}}_{\delta}=\left|\overrightarrow{\mathrm{C}}_{3} \overrightarrow{\mathrm{X}_{\delta}}(\mathrm{t})-\overrightarrow{\mathrm{X}}\right| \\
\overrightarrow{\mathrm{X} \alpha}=\overrightarrow{\mathrm{X} 1}-\overrightarrow{\mathrm{A} 1} \times \overrightarrow{\mathrm{D} \alpha} \\
\overrightarrow{\mathrm{X}_{\beta}}=\overrightarrow{\mathrm{X}_{2}}-\overrightarrow{\mathrm{A}_{2}} \times \overrightarrow{\mathrm{D}_{\beta}} \\
\overrightarrow{\mathrm{X}_{\delta}}=\overrightarrow{\mathrm{X}_{3}}-\overrightarrow{\mathrm{A}_{3}} \times \overrightarrow{\mathrm{D}_{\delta}}
\end{array}\right\}
$$

Now the position of pack can be updated by (14) and it is assumed to be the best solution as compared to other members. The flow chart of GWO is shown in Figure 3. (b). The tuned parameters of GWO are number of search parameter $(n)=30$, maximum number of iterations $=100$. 


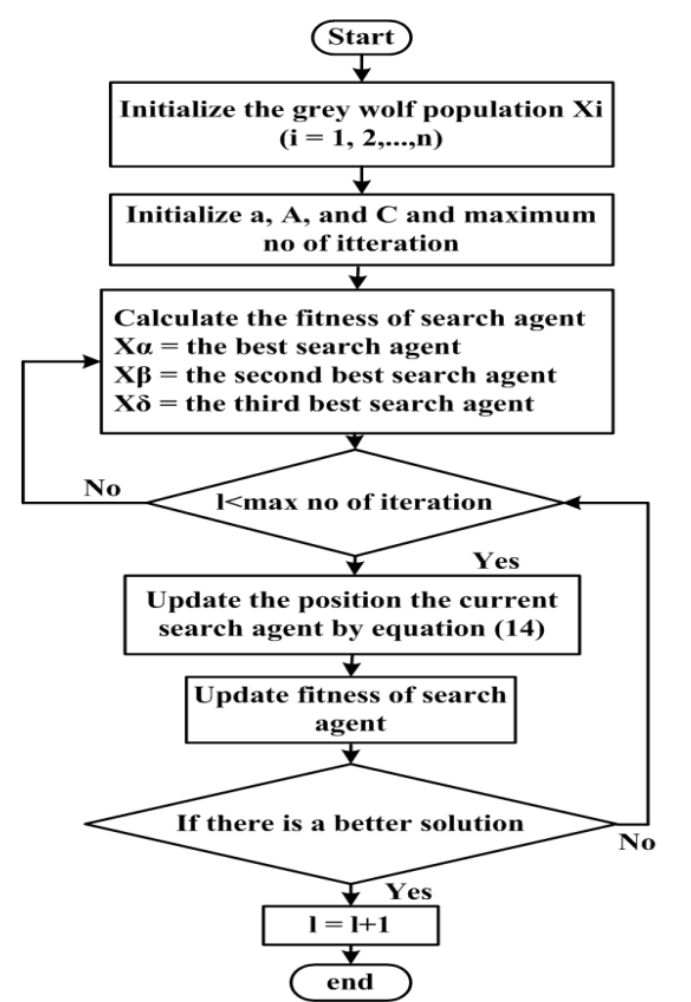

Figure 3. (b) Flowchart of grey wolf optimization algorithm

\subsection{Grass-Hopper Algorithm}

Shahrzad et al. proposed the Grass-hopper algorithm (GHA) [31, 32] based on the swarm behavior of grasshoppers. They are familiarly known as insects but considered as a pest. Generally, the grasshopper is individual in nature, but forms as a swarm with the larger size in number. This swarm possesses a unique characteristic of slow-step movements. The nymph grasshopper jump and moves like rolling cylinders with millions in number and eats all the plants that come in their path. After transforming into adults, swarm formation occurs and migrates over larger distances. The swarming behavior of grasshoppers in a d-dimension is given by (15).

$$
X_{i}^{d}=\sum_{\substack{j=1 \\ j \neq i}}^{N} s\left|X_{j}-X_{i}\right| \frac{X_{j}-X_{i}}{d_{i j}}-g \Phi_{g}+u \mathbb{E}_{w}
$$

The parameter (c) is balances the exploration and exploitation [29] and is given by (16).

$$
\mathrm{c}=\mathrm{c}_{\max }-\mathrm{AL}\left(\frac{\mathrm{c}_{\max }-\mathrm{c}_{\min }}{\mathrm{L}}\right)
$$

In this work the turned parameters of the GHA are search agents number $\mathrm{n}=20$, maximum number of iteration $(\mathrm{L})=$ 100 , intensity of attraction (IA) $=0.5$ and attractive length $(\mathrm{AL})=1.5$. The flow cart of GHA is shown in Figure 3. (c) The optimum global value is achieved with fewer iterations number. Moreover, it provides accurate and takes less time for convergence with simple operations.

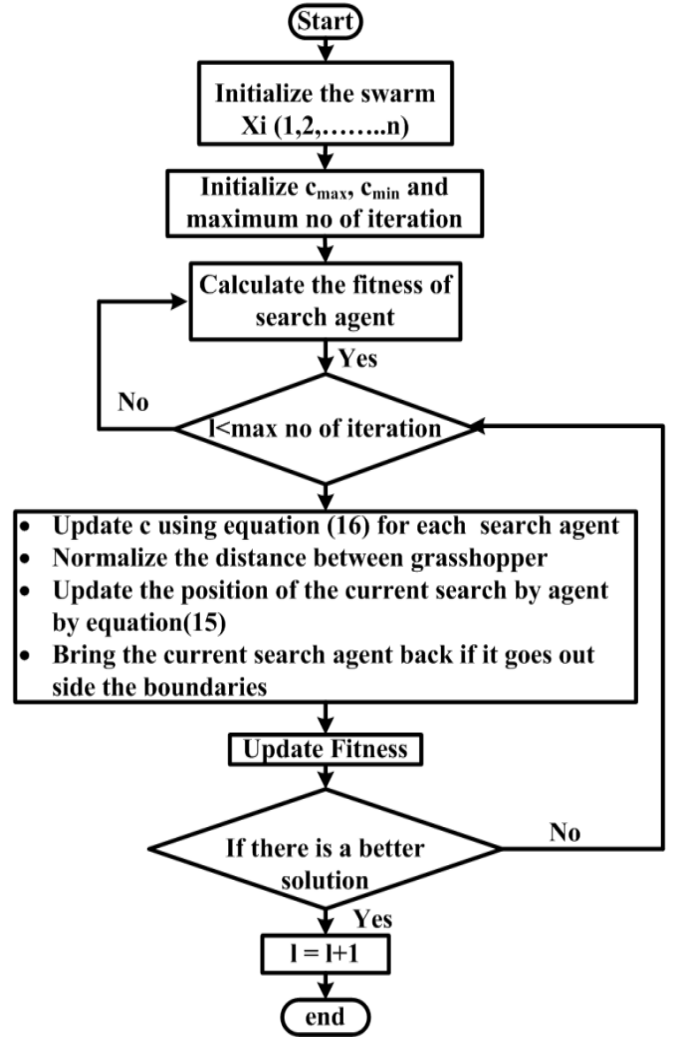

Figure 3. (c) Flowchart of grass hopper algorithm

\section{Results and Analysis}

\subsection{Comparison of System Responses with Various Controllers like PID, TID and I-TD}

The system in Figure 1 is considered and is provided with controllers like PID, TID and the proposed I-TD. The controller parameters are optimized by the GHA and the optimum value are presented in Table 1. (a). The dynamics responses of the system with various controllers are shown in Figure 4. (a) - 4. (d). The indices values such as over-shoot (OS), under-shoot (US) and settling-time (ST) are tabulated in Table-1. (b). From Figure 4 and Table 1. (b) we can clearly observe that the system with I-TD controller gives satisfactory performance than others in terms of US, $\mathrm{OS}$, and ST.

Table 1. (a) GHA optimized controller gains and

\begin{tabular}{|c|c|}
\hline PID & $\begin{array}{l}\mathrm{K}_{\text {P,PID1 }}=0.8258, \mathrm{~K}_{\mathrm{I}, \mathrm{PID} 1}=0.8258, \mathrm{~K}_{\mathrm{D}, \mathrm{PID} 1}=0.8258, \\
\mathrm{~K}_{\mathrm{P}, \mathrm{PID} 2}=0.2452, \mathrm{KI}_{\text {,PID2 }}=0.2452, \mathrm{~K}_{\mathrm{D}, \mathrm{PID} 2}=0.2452, \\
\mathrm{~K}_{\text {P,PID3 }}=0.7469, \mathrm{~K}_{\mathrm{I}, \mathrm{PID} 3}=0.7469, \mathrm{~K}_{\mathrm{D}, \mathrm{IID} 3}=0.7469 .\end{array}$ \\
\hline TID & $\begin{array}{l}\mathrm{K}_{\mathrm{T}, \mathrm{TID} 1}=0.9621, \mathrm{~K}_{\mathrm{I}, \mathrm{TID} 1}=0.5635, \mathrm{~K}_{\mathrm{D}, \mathrm{TID} 1}=0.2082 \\
\mathrm{~N}_{\mathrm{TID} 1}=4.9121, \mathrm{~K}_{\mathrm{T}, \mathrm{TID} 2}=0.0476, \mathrm{~K}_{\mathrm{I}, \mathrm{TID} 2}=0.4533, \\
\mathrm{~K}_{\mathrm{D}, \mathrm{TID} 2}=0.1692, \mathrm{~N}_{\mathrm{TID} 2}=2.7597, \mathrm{~K}_{\mathrm{T}, \mathrm{TID} 3}=0.0945, \\
\mathrm{~K}_{\mathrm{I}, \mathrm{TID} 3}=0.0116, \mathrm{~K}_{\mathrm{D}, \mathrm{TID} 3}=0.2478, \mathrm{~N}_{\mathrm{TID} 3}=2.8668 .\end{array}$ \\
\hline
\end{tabular}
parameters of PID, TID and I-TD 
$\mathrm{K}_{\mathrm{T}, \mathrm{I}-\mathrm{TD} 1}=0.7111, \mathrm{~K}_{\mathrm{I}, \mathrm{I}-\mathrm{TD} 1}=0.2304, \mathrm{~K}_{\mathrm{D}, \mathrm{I}-\mathrm{TD} 1}=0.0344$,

$\mathrm{N}_{\mathrm{I}-\mathrm{TD} 1}=2.0780, \mathrm{~K}_{\mathrm{T}, \mathrm{I}-\mathrm{TD} 2}=0.5741, \mathrm{~K}_{\mathrm{I}, \mathrm{I}-\mathrm{TD} 2}=0.0901$,

I-TD $\mathrm{K}_{\mathrm{D}, \mathrm{I}-\mathrm{TD} 2}=0.0136, \mathrm{~N}_{\mathrm{I}-\mathrm{TD} 2}=2.0079, \mathrm{~K}_{\mathrm{T}, \mathrm{I}-\mathrm{TD} 3}=0.0804$, $\mathrm{K}_{\mathrm{I}, \mathrm{I}-\mathrm{TD} 3}=0.6756, \mathrm{~K}_{\mathrm{D}, \mathrm{I}-\mathrm{TD} 3}=0.1901, \mathrm{~N}_{\mathrm{I}-\mathrm{TD} 3}=6.6617$.

Table 1. (b) Comparison of system dynamic responses with various controllers

\begin{tabular}{ccccc}
\hline Characteristics & & PID & TID & I-TD \\
\hline \multirow{3}{*}{$\Delta \mathrm{F}_{1}$} & OS & 0.0017 & 0.0018 & 0.0009 \\
& US & 0.0089 & 0.0068 & 0.0062 \\
& ST & 63.130 & 61.400 & 22.970 \\
\hline \multirow{2}{*}{$\Delta \mathrm{F}_{2}$} & OS & 0.0038 & 0.0038 & 0.0014 \\
& US & 0.0073 & 0.0068 & 0.0057 \\
& ST & 85.600 & 31.170 & 27.610 \\
\hline \multirow{2}{*}{$\Delta$ Ptie $_{12}$} & OS & 0.0052 & 0.0038 & 0.0034 \\
& US & 0.0015 & 0.0008 & 0.0001 \\
& ST & 94.330 & 83.770 & 25.250 \\
\hline \multirow{2}{*}{$\Delta$ Ptie $31^{31}$} & OS & 0.0025 & 0.0023 & 0.0019 \\
& US & 0.0020 & 0.0011 & 0.0008 \\
& ST & 84.600 & 33.050 & 21.870 \\
\hline
\end{tabular}

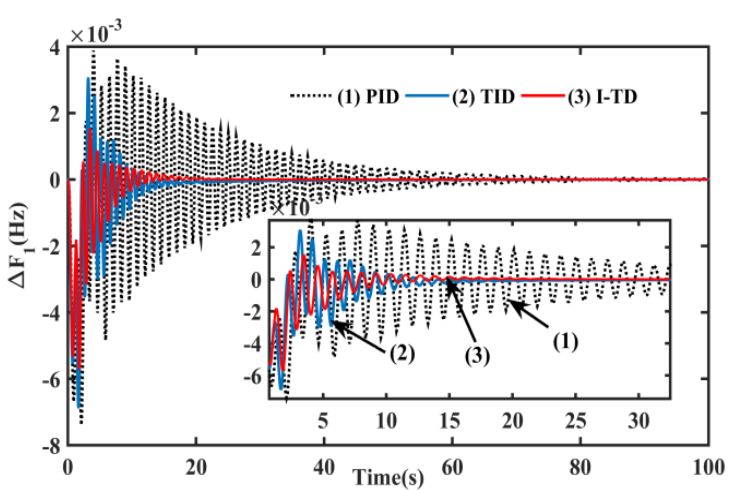

Figure 4. (a)

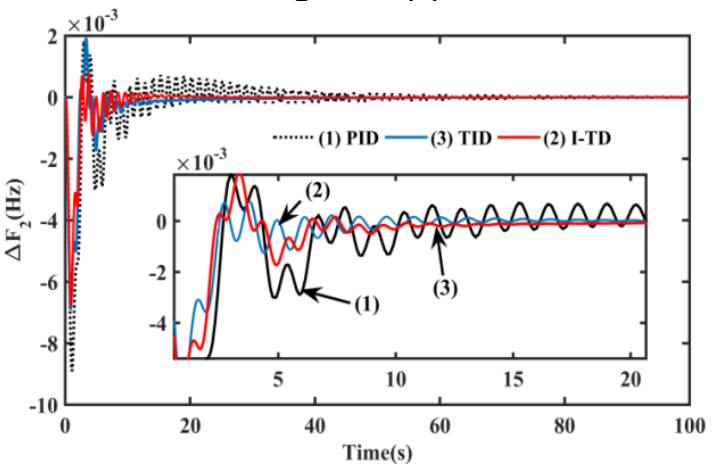

Figure 4. (b)

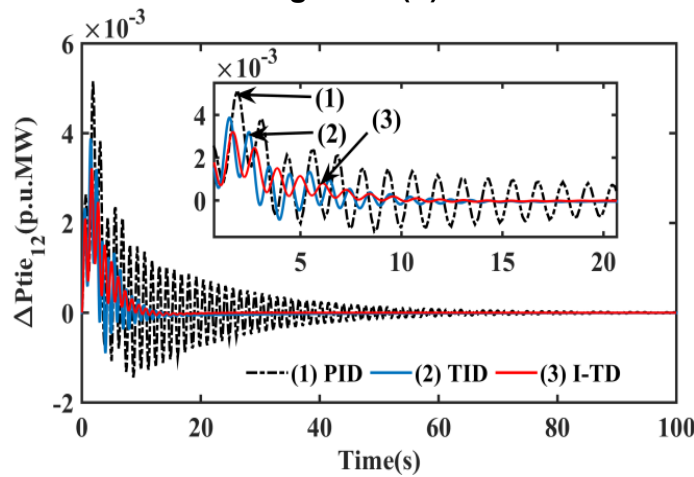

Figure 4. (c)

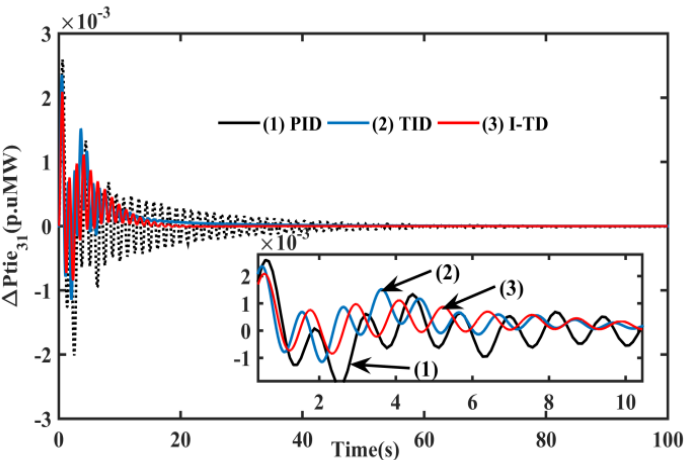

Figure 4. (d)

Figure 4. Dynamic response comparison of the system with PID, TID and I-TD controllers vs. time. (a) Frequency deviation in area-1, (b) Frequency deviation in area-2 (c) Tie-power deviation among area-1 and area-2 and, (d) Tiepower deviation among area- 3 and area- 1

\subsection{System Dynamics for Various Algorithms Considering I-TD Controller}

In this section, the best controller found in section-5.1 is optimized with different algorithms such as FA, GWO and GHA. The obtained dynamic responses are compared and are shown in Figure 5. (a) to 5. (c). The optimized I-TD controller gains and parameter with FA, GWO and GHA are noted in Table 2. (a) and Table 1. (a). The indices values such as over-shoot (OS), under-shoot (US) and settling-time (ST) are tabulated in Table 2. (b). After critical observation of Figure 5 and Table 2. (b), it can be conclude that with GHA optimized controller provides better dynamic responses with lesser OS, US, and ST in comparison to FA and GWO. Moreover, from the convergences curve in Figure 5. (d) and value of $\mathrm{J}_{\mathrm{ISE}}$ in Table 2. (b) reveals that the GHA converge faster with less $\mathrm{J}_{\text {ISE }}$ value than others. This validates that the obtain optimal value of controller parameters with GHA is more efficient than other optimization techniques.

Table 2 (a). Optimum gains and parameter of I-TD controller with various algorithms like FA, GWO and $\mathrm{GHA}$

$\mathrm{K}_{\mathrm{T}, \mathrm{I}-\mathrm{TD} 1}=0.1642, \mathrm{~K}_{\mathrm{I}, \mathrm{I}-\mathrm{TD} 1}=0.7313, \mathrm{~K}_{\mathrm{D}, \mathrm{I}-\mathrm{TD} 1}=0.9856$, $\mathrm{N}_{\mathrm{I}-\mathrm{TD} 1}=6.0328, \mathrm{~K}_{\mathrm{T}, \mathrm{I}-\mathrm{TD} 2}=0.7182, \mathrm{~K}_{\mathrm{I}, \mathrm{I}-\mathrm{TD} 2}=0.5863$,

FA $\mathrm{K}_{\mathrm{D}, \mathrm{I}-\mathrm{TD} 2}=0.7923, \mathrm{~N}_{\mathrm{I}-\mathrm{TD} 2}=5.8247, \mathrm{~K}_{\mathrm{T}, \mathrm{I}-\mathrm{TD} 3}=0.6696$, $\mathrm{K}_{\mathrm{I}, \mathrm{I}-\mathrm{TD} 3}=1.0000, \mathrm{~K}_{\mathrm{D}, \mathrm{I}-\mathrm{TD} 3}=0.9905, \mathrm{~N}_{\mathrm{I}-\mathrm{TD} 3}=4.0270$.

$\mathrm{K}_{\mathrm{T}, \mathrm{I}-\mathrm{TD} 1}=0.7588, \mathrm{~K}_{\mathrm{I}, \mathrm{I}-\mathrm{TD} 1}=0.4510, \mathrm{~K}_{\mathrm{D}, \mathrm{I}-\mathrm{TD} 1}=0.6235$, $\mathrm{N}_{\mathrm{I}-\mathrm{TD} 1}=5.9233, \mathrm{~K}_{\mathrm{T}, \mathrm{I}-\mathrm{TD} 2}=0.9853, \mathrm{~K}_{\mathrm{I}, \mathrm{I}-\mathrm{TD} 2}=0.1810$,

GWO $\mathrm{K}_{\mathrm{D}, \mathrm{I}-\mathrm{TD} 2}=0.9956, \mathrm{~N}_{\mathrm{I}-\mathrm{TD} 2}=2.0574, \mathrm{~K}_{\mathrm{T}, \mathrm{I}-\mathrm{TD} 3}=0.7612$, $\mathrm{K}_{\mathrm{I}, \mathrm{I}-\mathrm{TD} 3}=0.9955, \mathrm{~K}_{\mathrm{D}, \mathrm{I}-\mathrm{TD} 3}=0.9999, \mathrm{~N} \mathrm{I}-\mathrm{TD} 3=5.8820$.

Table 2. (b) Comparison of system dynamic responses with various algorithms

\begin{tabular}{ccccc}
\hline Characteristics & & FA & GWO & GHA \\
\hline \multirow{2}{*}{$\Delta \mathrm{F}_{1}$} & OS & 0.0025 & 0.0016 & 0.0014 \\
& US & 0.0063 & 0.0057 & 0.0057
\end{tabular}




\begin{tabular}{ccccc} 
& ST & 31.670 & 30.120 & 27.610 \\
\hline & OS & 0.0032 & 0.0036 & 0.0034 \\
$\Delta$ Ptie $_{12}$ & US & 0.0004 & 0.0003 & 0.0001 \\
& ST & 31.390 & 33.750 & 25.250 \\
\hline \multirow{2}{*}{$\Delta$ Ptie $_{31}$} & OS & 0.0023 & 0.0020 & 0.0019 \\
& US & 0.0014 & 0.0010 & 0.0008 \\
& ST & 36.980 & 31.210 & 21.870 \\
\hline J $_{\text {ISE }}$ & 0.000568 & 0.000520 & 0.000413 \\
\hline
\end{tabular}

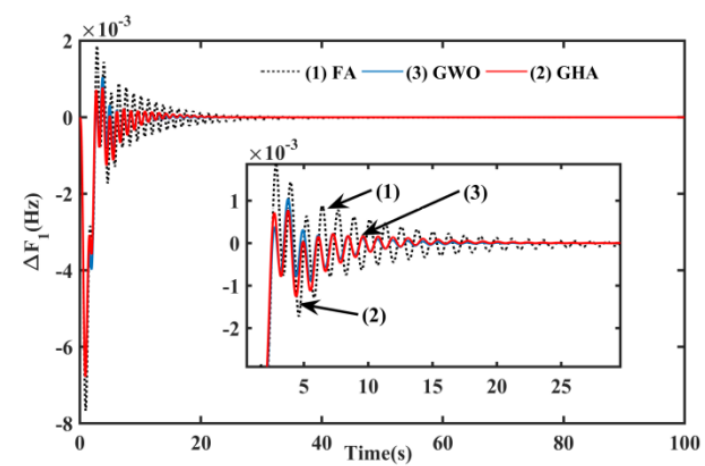

Figure 5. (a)

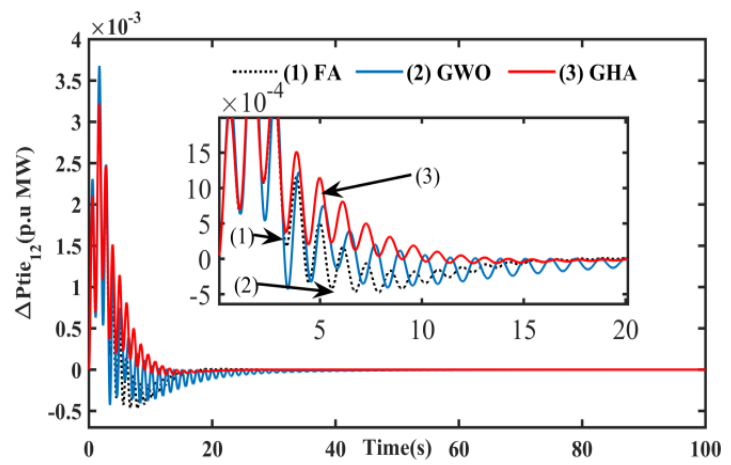

Figure 5. (b)

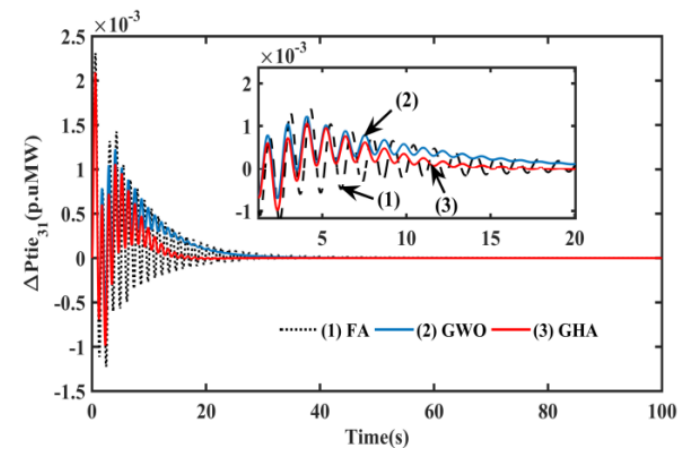

Figure 5. (c)

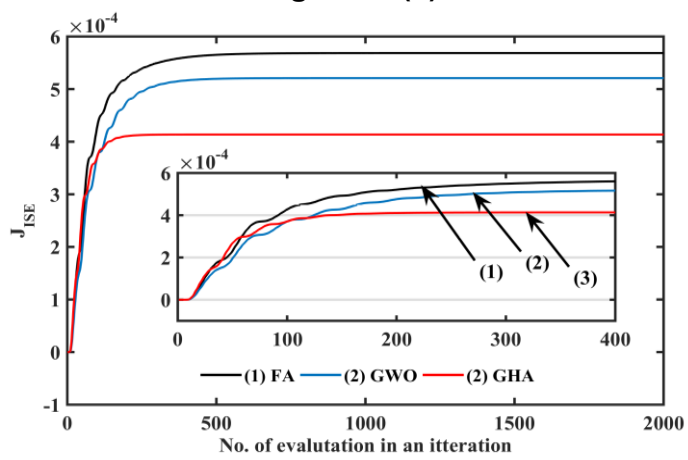

Figure 5. (d)
Figure 5. Comparison of system dynamic responses and convergence characteristics with FA, GWO and GHA. (a) Frequency deviation in area-1, (b) Tie-power deviation among area-1 and area-2, (c) Tie-power deviation among area-3 and area-1 and (d) convergence characteristic comparison.

\subsection{Sensitivity Analysis to Check the Robustness of the Proposed I-TD Controller with GHA}

Now in this section, dynamics responses of the considered system are examined at different loading conditions i.e., $-20 \%$ and $+20 \%$ from their nominal values such as $30 \%$ and $70 \%$. The dynamics responses are obtained with the best controller and the best optimization technique obtained from section-5.1 and section-5.2. The optimum parameters of the I-TD controller with GHA at varied conditions are listed in Table 3. The obtained dynamic responses are compared with the nominal conditions and are shown in Figure 6. (a) - 6. (d). From Figure 6 it is observed that the responses at different loading conditions are almost similar and need not to be reset again from nominal condition.

Table 3. Optimum gains and parameter of I-TD controller with $\mathrm{GHA}$ at various loading conditions $\mathrm{K}_{\mathrm{T}, \mathrm{I}-\mathrm{TD} 1}=0.4125, \mathrm{~K}_{\mathrm{I}, \mathrm{I}-\mathrm{TD} 1}=0.1484, \mathrm{~K}_{\mathrm{D}, \mathrm{I}-\mathrm{TD} 1}=$ $0.9936, \mathrm{~N}_{\mathrm{I}-\mathrm{TD} 1}=2.1475, \mathrm{~K}_{\mathrm{T}, \mathrm{I}-\mathrm{TD} 2}=0.9760, \mathrm{~K}_{\mathrm{I}, \mathrm{I}-}$

At 30\% TD2 $=0.1374, \mathrm{~K}_{\mathrm{D}, \mathrm{I}-\mathrm{TD} 2}=0.9979, \mathrm{~N}_{\mathrm{I}-\mathrm{TD} 2}=5.4764$, loading $\mathrm{K}_{\mathrm{T}, \mathrm{I}-\mathrm{TD} 3}=0.6789, \mathrm{~K}_{\mathrm{I}, \mathrm{I}-\mathrm{TD} 3}=0.9972, \mathrm{~K}_{\mathrm{D}, \mathrm{I}-\mathrm{TD} 3}=$ $0.9972, \mathrm{~N}_{\mathrm{I}-\mathrm{TD} 3}=1.674$.

$\mathrm{K}_{\mathrm{T}, \mathrm{I}-\mathrm{TD} 1}=0.8915, \mathrm{~K}_{\mathrm{I}, \mathrm{I}-\mathrm{TD} 1}=0.2424, \mathrm{~K}_{\mathrm{D}, \mathrm{I}-\mathrm{TD} 1}=$ At $70 \% \quad 0.3698, \mathrm{~N}_{\mathrm{I}-\mathrm{TD} 1}=2.6291, \mathrm{~K}_{\mathrm{T}, \mathrm{I}-\mathrm{TD} 2}=0.9992, \mathrm{~K}_{\mathrm{I}, \mathrm{I}-}$ loading $\mathrm{TD}_{2}=0.0954, \mathrm{~K}_{\mathrm{D}, \mathrm{I}-\mathrm{TD} 2}=0.8942, \mathrm{~N}_{\mathrm{I}-\mathrm{TD} 2}=3.8405$, $\mathrm{K}_{\mathrm{T}, \mathrm{I}-\mathrm{TD} 3}=0.6515, \mathrm{~K}_{\mathrm{I}, \mathrm{I}-\mathrm{TD} 3}=0.7823, \mathrm{~K}_{\mathrm{D}, \mathrm{I}-\mathrm{TD} 3}=$ $0.9913, \mathrm{~N}_{\mathrm{I}-\mathrm{TD} 3}=4.7690$.

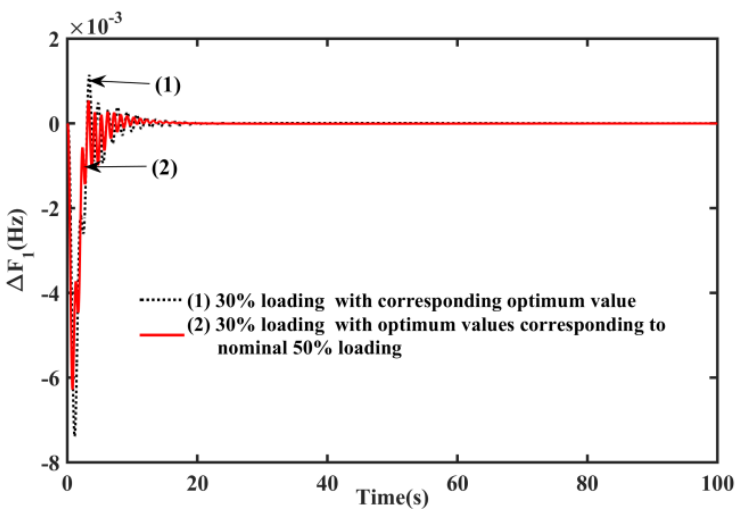

Figure 6. (a) 


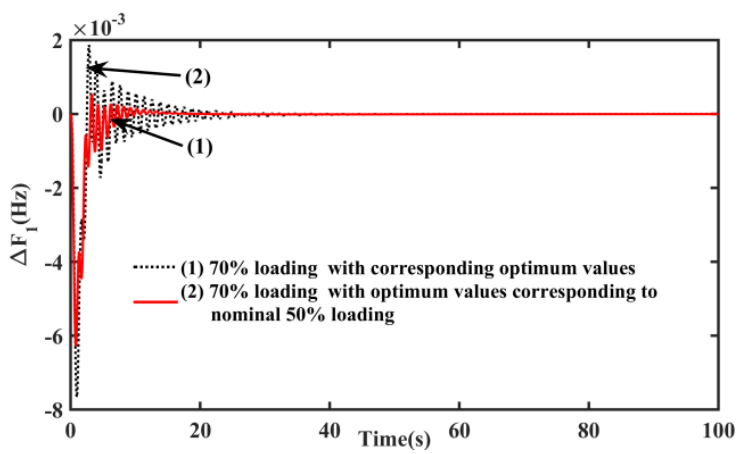

Figure 6. (b)

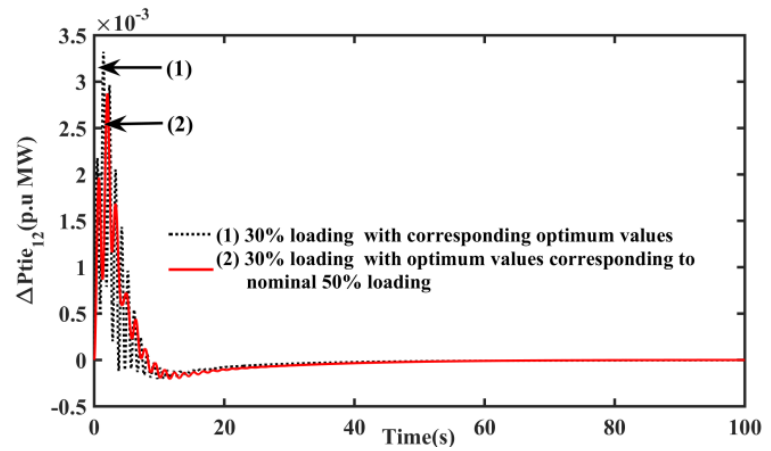

Figure 6. (c)

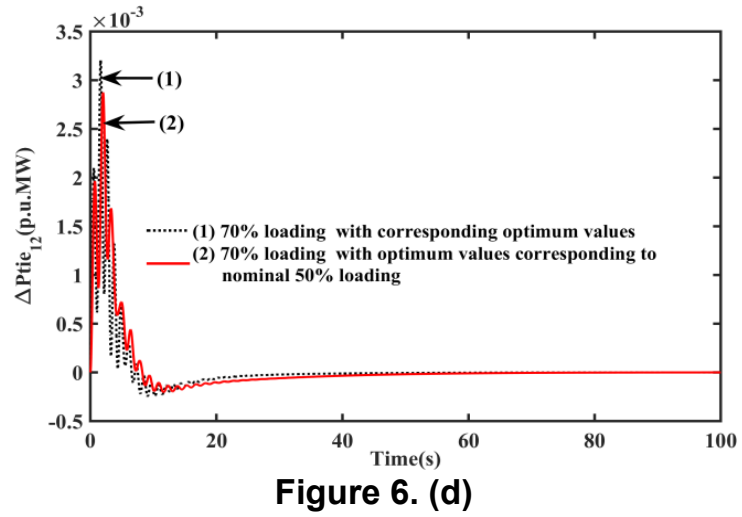

Figure 6. Dynamic response comparison of the system at varied with nominal condition vs. time (a) Frequency deviation in area-1 at 30\% loading condition, (b) Frequency deviation in area-1 at $70 \%$ loading condition, (c) Tie-power deviation among area- 1 and area-2 at $30 \%$ loading condition and (d) Tie-power deviation among area-1 and area-2 at $70 \%$ loading condition

\section{Conclusion}

A maiden effort was made to integrate the I-TD controller for three-area multi-source AGC system. The controller gains and parameters are optimized by various metaheuristic algorithms namely firefly algorithm (FA), grey wolf algorithm (GWO) and grasshopper algorithm (GHA). The system dynamics corresponding to I-TD controller are compared with PID, TID and outperforms in terms of settling time, peak overshoot and peak undershoot. Moreover, it is also observed that the system dynamics with I-TD and GHA outperforms over FA and GWO in terms of convergence and values of objective function. Further, sensitivity analysis explores that the system responses at different loading and nominal conditions are more or less same. Furthermore, various forms of I-TD controller can also be explored and can be extended under restructured power system, combined control of voltage and frequency.

\section{Appendix}

At nominal condition:

frequency $(\mathrm{F})=60 \mathrm{~Hz}$, Loading $=50 \%$, Tie-power $\left(\mathrm{T}_{12}\right.$ $\left.=\mathrm{T}_{23}=\mathrm{T}_{31}\right)=0.086 \mathrm{puMW} / \mathrm{rad}, \mathrm{Kp}_{1}=\mathrm{Kp}_{2}=\mathrm{Kp}_{3}=$ $120 \mathrm{~Hz} / \mathrm{pu}, \mathrm{R}_{1}=\mathrm{R}_{2}=\mathrm{R}_{3}=2.4 \mathrm{~Hz} / \mathrm{pu}, \mathrm{B}_{1}=\mathrm{B}_{2}=\mathrm{B}_{3}=$ $0.425 \mathrm{MW} / \mathrm{Hz}, \mathrm{T}_{\mathrm{p} 1}=\mathrm{T}_{\mathrm{p} 2}=\mathrm{T}_{\mathrm{p} 3}=20 \mathrm{~s}, \mathrm{~T}_{\mathrm{g} 12}=\mathrm{T}_{\mathrm{g} 21}=\mathrm{T}_{\mathrm{g} 22}$ $=\mathrm{T}_{\mathrm{g} 32} 0.08 \mathrm{~s}, \mathrm{~T}_{\mathrm{t} 12}=\mathrm{T}_{\mathrm{t} 21}=\mathrm{T}_{\mathrm{t} 22}=\mathrm{T}_{\mathrm{t} 32}=0.3 \mathrm{~s}, \mathrm{~K}_{\mathrm{r} 12}=\mathrm{K}_{\mathrm{r} 21}=$ $\mathrm{K}_{\mathrm{r} 22}=\mathrm{K}_{\mathrm{r} 31}=0.5, \mathrm{~T}_{\mathrm{r} 12}=\mathrm{T}_{\mathrm{r} 21}=\mathrm{T}_{\mathrm{r} 22}=\mathrm{T}_{\mathrm{r} 31}=10 \mathrm{~s}, \mathrm{~K}_{\mathrm{ST} 11}=$ $1.8, \mathrm{~T}_{\mathrm{ST} 11}=1.8 \mathrm{~s}, \mathrm{~T}_{\mathrm{gST}}=1.0 \mathrm{~s}, \mathrm{~T}_{\mathrm{Tst}}=3.0 \mathrm{~s} \mathrm{~K}_{\mathrm{HP} 32}=1.25$, $\mathrm{T}_{\mathrm{HP} 32}=0.041 \mathrm{~s}, \mathrm{~T}_{\mathrm{BP} 32}=0.6 \mathrm{~s}, \mathrm{~K}_{\mathrm{DP} 32}=1.4, \mathrm{~K}_{\mathrm{PC} 32}=0.8$, area participation factor $\left(\mathrm{apf}_{\mathrm{ij}}\right)=0.5, \mathrm{SLP}=1 \%$, solar insolation of $=0.01 \mathrm{p} . \mathrm{u} \mathrm{W} / \mathrm{m}^{2}$, delay $=0.02 \mathrm{~s}$.

\section{References}

[1] P.Kundur.(1994)"Power System Stability and Control," TATA McGraw-Hill, New Delhi,.

[2] C. Concordia and L. K. Kirchmayer.(1954)"Tie-Line Power and Frequency Control of Electric Power Systems - Part II "Trans. of the American Institute of Elect. Engineers. Part III: Pow. Apparatus and Syst., vol. 73, no. 2, pp. 133-146.

[3] Elgerd, O.(1983)"The enrgy system in steady state-the control problem," Electric Energy System Theory: an introduction, 2nd ed. New York: McGraw-Hill,pp.299-361,

[4] Elgerd,O.I.and Fosha C. E.(1970) "Optimum Megawatt-Frequency Control of Multiarea Electric Energy Systems," in IEEE Trans. Pow. Apparatus and Syst., 89, pp. 556-563, April

[5] Nanda, J., Mishra,S., and Saikia,L.C.(2009) "Maiden Application of Bacterial Foraging-Based Optimization Technique in Multiarea Automatic Generation Control,"IEEE Trans. Power Syst.,24,pp. $602-609$.

[6] A. Rahman, L. C. Saikia and N. Sinha.(2016)"Maiden application of hybrid pattern search-biogeography based optimisation technique in automatic generation control of a multi-area system incorporating interline power flow controller, " IET Gen., Trans. \& Distrib, 10, pp. 1654-1662.

[7] Taylor,C. W., Lee, K. Y. and Dave,D. P.(1979) "Automatic Generation Control Analysis With Governor Dead band Effects," IEEE Trans. Power Apparatus \&Syst., 98, pp. 2030-2036,

[8] Hari,L., Kothari,M. L., and Nanda, J.( 1991) "Optimum selection of speed regulation parameters for automatic generation control in discrete mode considering generation rate constraints," IEE Proc. C - Gen., Trans. and Distrib.,138, pp. 401-406.

[9] Sharma Y. and Saikia L.C.,(2015). "Automatic generation control of a multi-area ST-thermal power system using Grey Wolf optimizer algorithm based 
classical controllers", Int. J. Electr. Power Energy Syst.,73: pp. 853-862,

[10] Tasnin,W.,Saikia,L.C.,Saha, A., Saha, D., and Rajbongshi, R. (2018) "Effect of Different Renewables and FACT Device on an Interconnected Thermal System Using SCA Optimized Fractional Order Cascade Controllers,"2nd Int. Conf. Power, Energy and Environment: Towards Smart Technology, Shillong, India, pp. 1-6.

[11] Saha,A.,and Saikia, L. C.(2018) "Combined application of redox flow battery and DC link in restructured AGC system in the presence of WTS and DSTS in distributed generation unit," IET Gen. Trans. \& Distrib., 12(9):pp. 2072-2085

[12] Nanda, J. and Saikia, L. C.(2008) "Comparison of performances of several types of classical controller in automatic generation control for an interconnected multiarea thermal system," Australasian Universities Pow. Eng. Conf., Sydney, NSW,pp. 1-6.

[13] Debbarma, S. and Saikia,L. C.(2011) "Effect of fractionalorder controller on automatic generation control of a multiarea thermal system," Int. Conf. Sustainable Energy and Intelligent Syst. Chennai, pp. 223-228.

[14] Panda, S., Patidar, N. P. and Kolhe, M. (2016)" Cascaded PD-PI controller for active power frequency control of two-area multi-units power system," IEEE Int. Conf. Power and Renewab. Energy, Shanghai, pp. 251-254.

[15] Morsali,J.,Zare,K. and Tarafdar,M.(2017)"MGSO optimised TID-based GCSC damping controller in coordination with AGC for diverse-GENCOs multiDISCOs power system with considering GDB and GRC non-linearity effects," IET Gener. TranS.,\& Distrib., 11,pp. 193-208.

[16] Lurie, B. J. and United States. (1993) "Three-parameter tunable tilt-integral-derivative (TID) controller", National Aeronautics and Space Administration, Washington, DC

[17] Esgandanian, Aysan \& Danishvar, Sebelan. (2016). "A Comparative Study on a Tilt-Integral-Derivative Controller with Proportional-Integral-Derivative Controller for a Pacemaker". Int. j. of advnced bio-tech. and research, 7,645650.

[18] Behera , A. Panigrahi, T. K. Ray,P. K. and Sahoo, A. K (2019)"A novel cascaded PID controller for automatic generation control analysis with renewable sources," IEEE J. Automatica Sinica, 6, pp.1438-1451.

[19] Babu, N. R. and Saikia, L. C ( 2019) "Automatic generation control of a solar thermal and dish-stirling solar thermal system integrated multi-area system incorporating accurate HVDC link model using crow search algorithm optimised FOPI Minus FODF controller," IET Renewab. Pow. Gen., 13, 2221-2231.

[20] Saha, D. and Saikia, L. C (2017) "Automatic generation control of a multi-area CCGT-thermal power system using stochastic search optimised integral minus proportional derivative controller under restructured environment, "IET Gen, Trans. \& Distrib., 11, pp. 3801-3813.

[21] Madan, K.J., Kumar, N., Bhatt, G. (2006) "Evaluation of traditional and nontraditional optimization techniques for determining well parameters from step-drawdown test data, "J. Hydrologic Eng., ASCE, 11, pp. 617-630.
[22] Kritika, V., Sahil, D., Sonia, J. (2017) “Analogy of traditional and modern optimization techniques in wireless sensor networks: a review", Int. J. Adv. Res. Comput. Commun. Eng., 6, pp. 175-178

[23] Behera, S. P., Biswal, A.,S amantrayS. S.,and Swain, B. (2018) "Hybrid power system frequency regulation using TID based robust controller design and differential evolution (DE) algorithm, "Tech. for SmartCity Energy Security and Pow., (ICSESP), Bhubaneswar, pp. 1-6.

[24] Nanda, J., Mishra S., and Saikia, L.C. (2009) "Maiden Application of Bacterial Foraging-Based Optimization Technique in Multiarea Automatic Generation Control," IEEE Trans. Pow. Syst., 24(2), pp. 602-609.

[25] Dash, P., Saikia, L.C, Sinha, N.(2015) "Comparison of performances of several FACTS devices using Cuckoo search algorithm optimized 2DOF controllers in multiarea AGC" Elect. Pow. Energy Syst., 65, pp 316-324.

[26] Yang, X.S.(2009) "Firefly Algorithm for Multimodal Optimization, Stochastic Algorithms: Foundations and Applications, " Lecture Notes in Computer Sciences, SAGA, pp 169-178

[27] Dash, P., Saikia, L. C., and Das, S. K (2014) "AGC of a multi-area hydro-thermal system with BES and firefly optimized PID controller," 2014 Eighteenth National Power Systems Conference (NPSC), Guwahati, pp. 16.

[28] Jagatheesan,K., Anand, B., S. Samanta, and Balas, V. E.,( 2019) "Design of a proportional-integral-derivative controller for an automatic generation control of multiarea power thermal systems using firefly algorithm," in IEEE/CAA Journal of Automatica Sinica, 6, pp. 503515.

[29] Seyedali M., and Andrew L., (2014) "Grey wolf optimizer Advances Engineering Software", 69, pp. $46-61$.

[30] Mate, N.,and Bhongade,S.,(2016) "Automatic generation control of two-area ST-thermal power plant optimized with grey wolf optimization," IEEE 7th Power India Int. Conf., Bikaner, pp. 1-6.

[31] Shahrzad Saremi, Seyedali Mirjalili, Andrew Lewis (2017). "Grasshopper Optimisation Algorithm: Theory and application, " Advances Engineering Software,105, pp. 30-47.

[32] Zeynali, M., Shahidi (2018) "Performance Assessment of Grasshopper Optimization Algorithm for Optimizing Coefficients of Sediment Rating Curve", AUT J. of Civil Engineering, 2(1).

[33] Raju, M., Saikia, L.C., Sinha, N. and Saha, D.(2017) Application of antlion optimizer technique in restructured automatic generation control of two-area hydro-thermal system considering governor dead band. Innovations Power and Advanced Computing Technologies, Vellore, pp.1-6.

[34] Rahman, A.,Saikia, L. C. and Sinha, N.(2016) "Maiden application of hybrid pattern search-biogeography based optimisation technique in automatic generation control of a multi-area system incorporating interline power flow controller, "IET Gener. Trans. \& Distrib., (10),pp.1654-1662. 